\title{
Editorial
}

\section{Ergos after Work}

_ Unser Ergotherapie-Angebot bei Thieme hat Nachwuchs bekommen: Wir haben eine „After Work Lecture“ ins Leben gerufen! Am 4. Juli 2014 bescheren wir Ihnen einen ganz besonderen Feierabend - mit Sekt, Häppchen, tollen Kollegen, einer großen Portion Autismus und einer wunderbaren Referentin!

_ Dr. Christine Preißmann wird den Abend mit viel Erfahrung, Wissen und vor allem mit Leben füllen. Die Ärztin ist selbst Asperger-Autistin und möchte dafür sensibilisieren, Kinder, Jugendliche und Erwachsene mit Autismus zu erkennen, ihre besonderen Fähigkeiten zu fördern und sie auf ihrem Lebensweg zu unterstützen.

_ Reservieren Sie sich den Abend des 4. Juli 2014, und packen Sie sämtliche Kollegen ein - Ergotherapeuten, Physiotherapeuten, Kinderärzte, Erzieher und Lehrer - und kommen Sie nach Ulm zum ulmkolleg! Alle Infos dazu finden Sie unter www.thieme.de/afterworklecture.

Ich freue mich auf Sie und einen wunderbaren Abend!

Herzlichst

Ihre

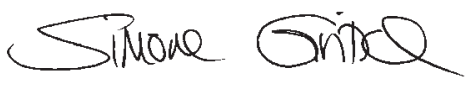

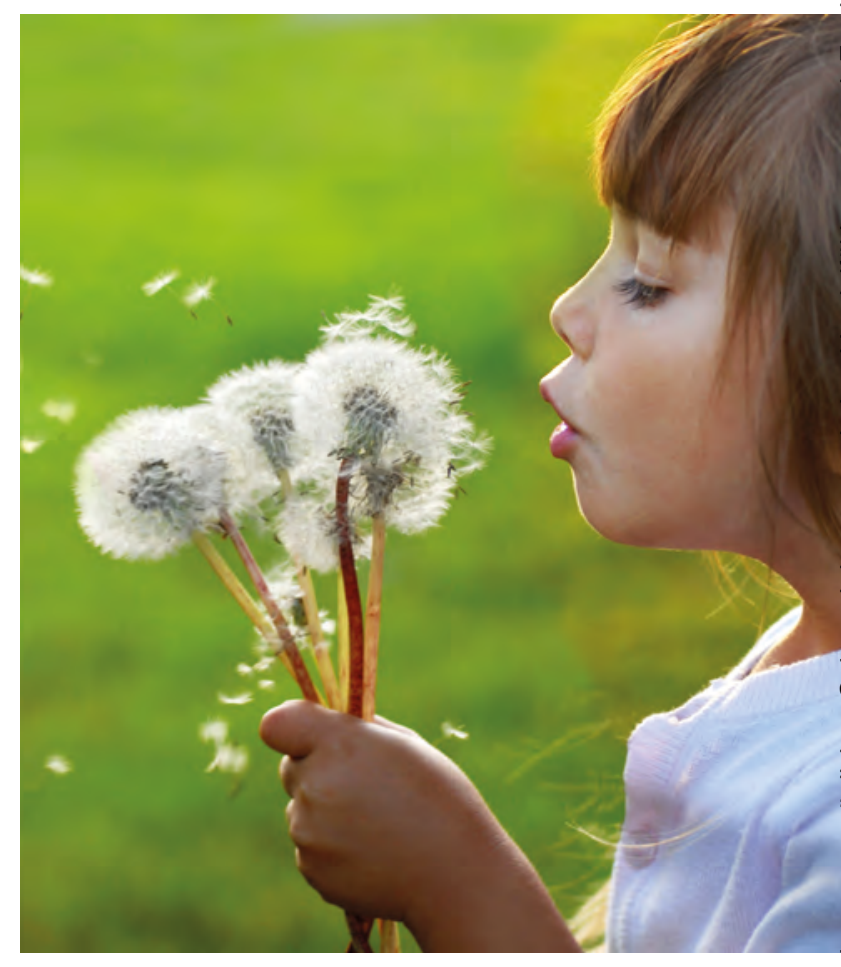

